\title{
New insights into the genetics of glioblastoma multiforme by familial exome sequencing
}

\author{
Christina Backes ${ }^{1, *}$, Christian Harz ${ }^{2}$, Ulrike Fischer ${ }^{2}$, Jana Schmitt $^{2}$, Nicole Ludwig $^{2}$, \\ Britt-Sabina Petersen ${ }^{3}$, Sabine C. Mueller ${ }^{1,2}$, Yoo-Jin Kim ${ }^{4}$, Nadine M. Wolf5, Hugo \\ A. Katus ${ }^{5}$, Benjamin Meder ${ }^{5}$ Rhoikos Furtwängler ${ }^{6}$, Andre Franke ${ }^{3}$, Rainer Bohle ${ }^{4}$, \\ Wolfram Henn'2, Norbert Graf', Andreas Keller ${ }^{1}$ and Eckart Meese ${ }^{2}$ \\ ${ }^{1}$ Clinical Bioinformatics, University of Saarland, Saarbrücken, Germany \\ 2 Institute of Human Genetics, University of Saarland, Medical School, Homburg, Germany \\ ${ }^{3}$ Institute of Clinical Molecular Biology, Christian-Albrechts-University Kiel, Haus Niemannsweg, Kiel, Germany \\ ${ }^{4}$ Department of Pathology, University of Saarland, Medical School, Building, Homburg, Germany \\ ${ }^{5}$ Department of Internal Medicine III, University of Heidelberg, Heidelberg, Germany \\ ${ }^{6}$ Pediatric Hematology and Oncology, University of Saarland, Medical School, Homburg, Germany \\ Correspondence to: Christina Backes, email: c.backes@mx.uni-saarland.de \\ Keywords: glioblastoma multiforme, next generation sequencing, bioinformatics \\ Received: October 02, $2014 \quad$ Accepted: December 09, $2014 \quad$ Published: December 10, 2014
}

This is an open-access article distributed under the terms of the Creative Commons Attribution License, which permits unrestricted use, distribution, and reproduction in any medium, provided the original author and source are credited.

\section{ABSTRACT}

Glioblastoma multiforme (GBM) is the most aggressive and malignant subtype of human brain tumors. While a family clustering of GBM has long been acknowledged, relevant hereditary factors still remained elusive. Exome sequencing of families offers the option to discover respective genetic factors.

We sequenced blood samples of one of the rare affected families: while both parents were healthy, both children were diagnosed with GBM. We report 85 homozygous non-synonymous single nucleotide variations (SNVs) in both siblings that were heterozygous in the parents. Beyond known key players for GBM such as ERBB2, PMS2, or CHI3L1, we identified over $\mathbf{5 0}$ genes that have not been associated to GBM so far. We also discovered three accumulative effects potentially adding to the tumorigenesis in the siblings: a clustering of multiple variants in single genes (e.g. PTPRB, CROCC), the aggregation of affected genes on specific molecular pathways (e.g. Focal adhesion or ECM receptor interaction) and genomic proximity (e.g. chr22. q12.2, chr1.p36.33). We found a striking accumulation of SNVs in specific genes for the daughter, who developed not only a GBM at the age of 12 years but was subsequently diagnosed with a pilocytic astrocytoma, a common acute lymphatic leukemia and a diffuse pontine glioma.

The reported variants underline the relevance of genetic predisposition and cancer development in this family and demonstrate that GBM has a complex and heterogeneous genetic background. Sequencing of other affected families will help to further narrow down the driving genetic causes for this disease.

\section{INTRODUCTION}

Gliomas are the most common primary brain tumors in adults and are associated with a generally very dismal prognosis. The most aggressive subtype is glioblastoma multiforme (GBM) with a median survival of 15 months after surgery and subsequent treatment with temozolomide
[1]. The age adjusted prognosis does not significantly differ between the two major histological subtypes, the primary GBMs that are diagnosed at an advanced stage and at a median age of approximately 60 years and the secondary GBMs that develop from preexisting low grade astrocytoma at a median age of 45 years [2]. Among brain tumors in childhood, GBM is a rather rare entity [3]. 
Numerous studies have focused on the genetics of this tumor to further dissect the underlying mechanisms and to contribute to a better prognosis. Over the last decade several genetic lesions including TP53 and PTEN mutations have been identified in glioblastoma tissue. Recently, sequencing of over 20,000 genes discovered an extended number of altered protein coding sequences including IDH1 (isocitrate dehydrognase) that were changed in more than $10 \%$ of GBM [4].

Although there is no established monogenic Mendelian syndrome of heritable gliomas, there is strong epidemiologic evidence of family clustering of this tumor. Familial gliomas occur in approximately 5\% of all glioma cases, the majority of which is associated with neoplastic syndromes like the Li-Fraumeni syndrome and neurofibromatosis type 1 [5]. As to the remaining familial cases, the influences of a shared environment and of the presumed hereditary components remain to be determined. Besides some cases indicative of an autosomal recessive mode of heredity, there was also anecdotal evidence for a dominant inheritance in few families [6]. Recently, a genome wide SNP linkage analysis supported the idea of a Mendelian predisposition to gliomas and specifically to a susceptibility locus at 17q12-21.32 [7].

Whole exome sequencing of affected families has been successfully applied to find genetic factors for various human pathologies, such as prostate cancer [8], Wilms tumor [9], breast cancer [10], hearing loss [11], and many other diseases. To find potential genetic factors linked to GBM tumorigenesis we performed whole exome sequencing of a rare familial case: while both parents were not diagnosed for any cancer, both siblings were diagnosed with a GBM. Following the diagnosis of a GBM the sister developed a pilocytic astrocytoma, a common acute lymphatic leukemia, and a diffuse glioma. The development of several tumors, particularly at such an early age indicates a genetic component. We sequenced germline DNA of the two affected siblings and their unaffected parents. For the two children, the GBM DNA has also been sequenced.

\section{RESULTS}

\section{History of a family with two siblings with glioblastoma}

In our study we consider a rare familial case of Glioblastoma multiforme (GBM). While both parents were healthy, two siblings were diagnosed with GBM. The brother was diagnosed at the age of 10 and the sister at the age of 12 years. The sister also developed a pilocytic infratentorial astrocytoma (WHO grade I), a common acute lymphatic leukemia and a diffuse pontine glioma. Both parents did not suffer from brain cancer or other cancer diseases. In the paternal lineage there were two ancestors with meningioma, one with ovarian carcinoma and one with colon carcinoma, each at advanced age. In the maternal lineage there were two ancestors with cancer including one with a prostate carcinoma and one with a melanoma. The pedigree is presented in Figure 1. We performed exome sequencing of germline DNA from both parents and of the siblings. Additionally, we also considered the variants in the GBM DNA of both tumors.

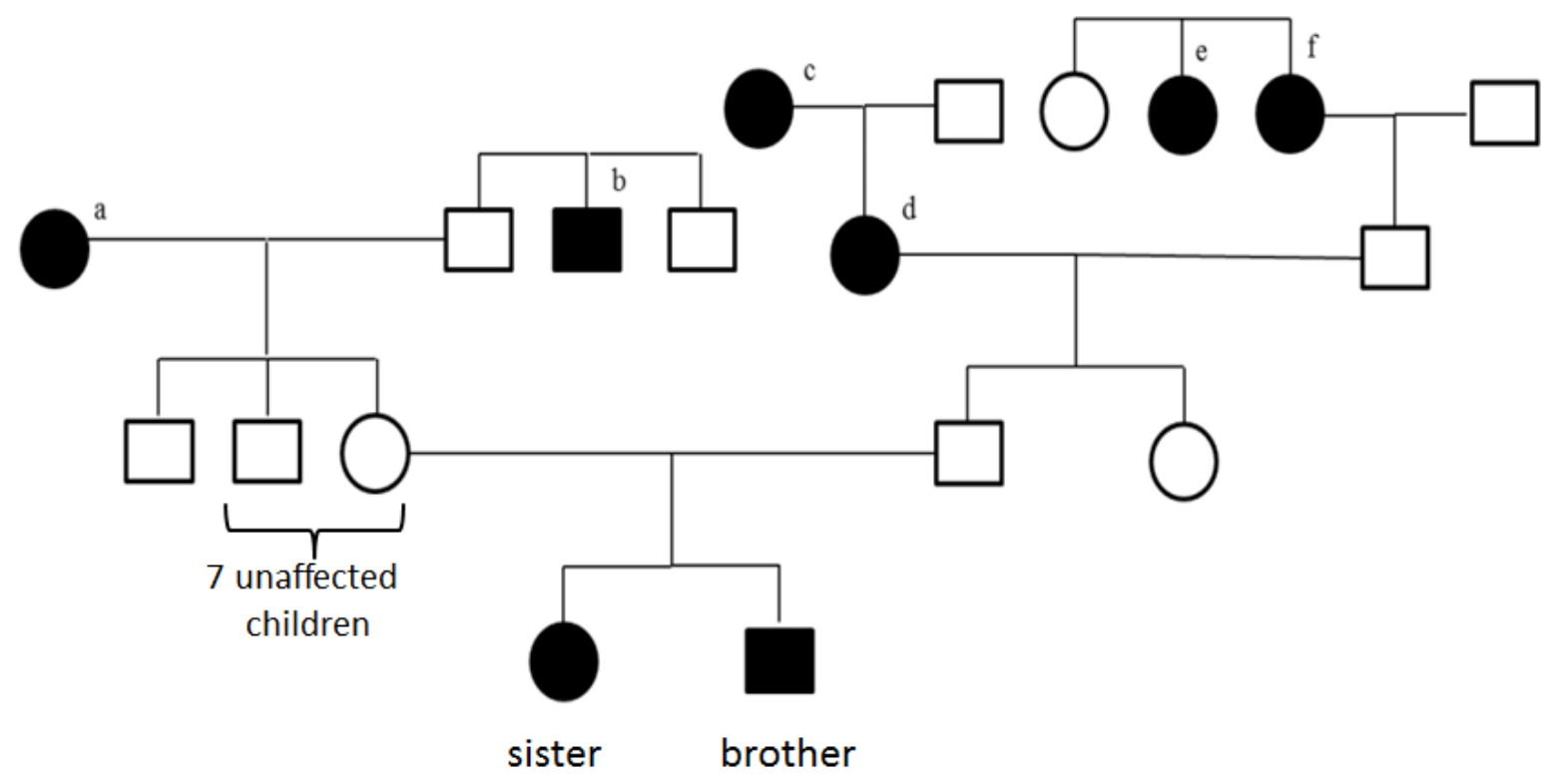

Figure 1: Family pedigree. ${ }^{a}$ melanoma at the age of 61 years, ${ }^{b}$ prostate carcinoma at the age of about 50 years, ${ }^{\mathrm{c}}$ meningioma at the age of 63 years, ${ }^{d}$ meningioma at the age of 86 years, ${ }^{\mathrm{e}}$ died at the age of about 50 years of ovarian cancer, ${ }^{\mathrm{f}}$ died at the age of 72 years of colon cancer. 


\section{Exome sequencing performance}

We performed exome sequencing for the glioblastoma tissue of the siblings, their blood samples and the blood samples of their parents. Details on the tumor samples are provided in Material and Methods. All samples were sequenced on a single lane on an IlluminaHiSeq2000, yielding a total of 475 million reads. Of these, $95 \%$ could be mapped to the human reference genome build hg19. After excluding reads that map to multiple locations, we obtained a mean coverage between $45 \mathrm{x}$ and $62 \mathrm{x}$. Between $77 \%$ and $83 \%$ of the targeted sequences were covered $\geq 20 \mathrm{x}$.

\section{SNV and indel analysis}

To discover SNVs and indels that may be causative for GBM we called variants for all six samples together using the GATK UnifiedGenotyper [13]. We discovered a total of 100,676 different variants, of which 83,394 passed the quality filters. Next, we applied ANNOVAR [14] for annotating the genes and class of SNPs and indels. According to this annotation, 18,626 exonic SNPs and indels were non-synonymous, including missense mutations, frameshifts, gains of stop codons and losses of stop codons. First we focused on variants that were homozygous in both children's germlines while being heterozygous in both parents' germlines. We report 85 such homozygous non-synonymous SNVs, mapping to
73 different genes. The respective mutations are listed in Table 1. Eight genes showed at least two such variants, including $F 5$ (four variants), CR1, AKAP1 (three variants each), ANKRD5, C15orf42, KIF7, ERBB2 and ABCA10 (two variants each). Next, we asked whether the variants have already been annotated in the GWAS catalogue, meaning that they have been already discovered in larger case / control studies. Altogether, 13 different SNPs are listed in the GWAS catalogue as related to glioblastoma. Interestingly, none of the 85 reported variants is associated with GBM. Beyond the effect of single variants on tumor development, the clustering of SNVs in single genes may also contribute to the generation of tumors. To address this issue, we calculated scores for each gene separately and performed a filtering to discover genes with most variants. We also investigated whether the $85 \mathrm{SNVs}$ in 73 genes accumulate at specific genomic positions or on certain molecular pathways.

\section{Cumulative scores of genes}

The variants listed in Table 1 indicate that certain genes may be more affected than others. In this analysis we just considered variants that were homozygous in the siblings and heterozygous in parents. Nonetheless, variants that are heterogeneous may also add to the pathogenicity. To acknowledge this fact, we defined a score for each gene: Each genomic position that is homozygous wild type obtains a score of 0 , heterozygous variants a score

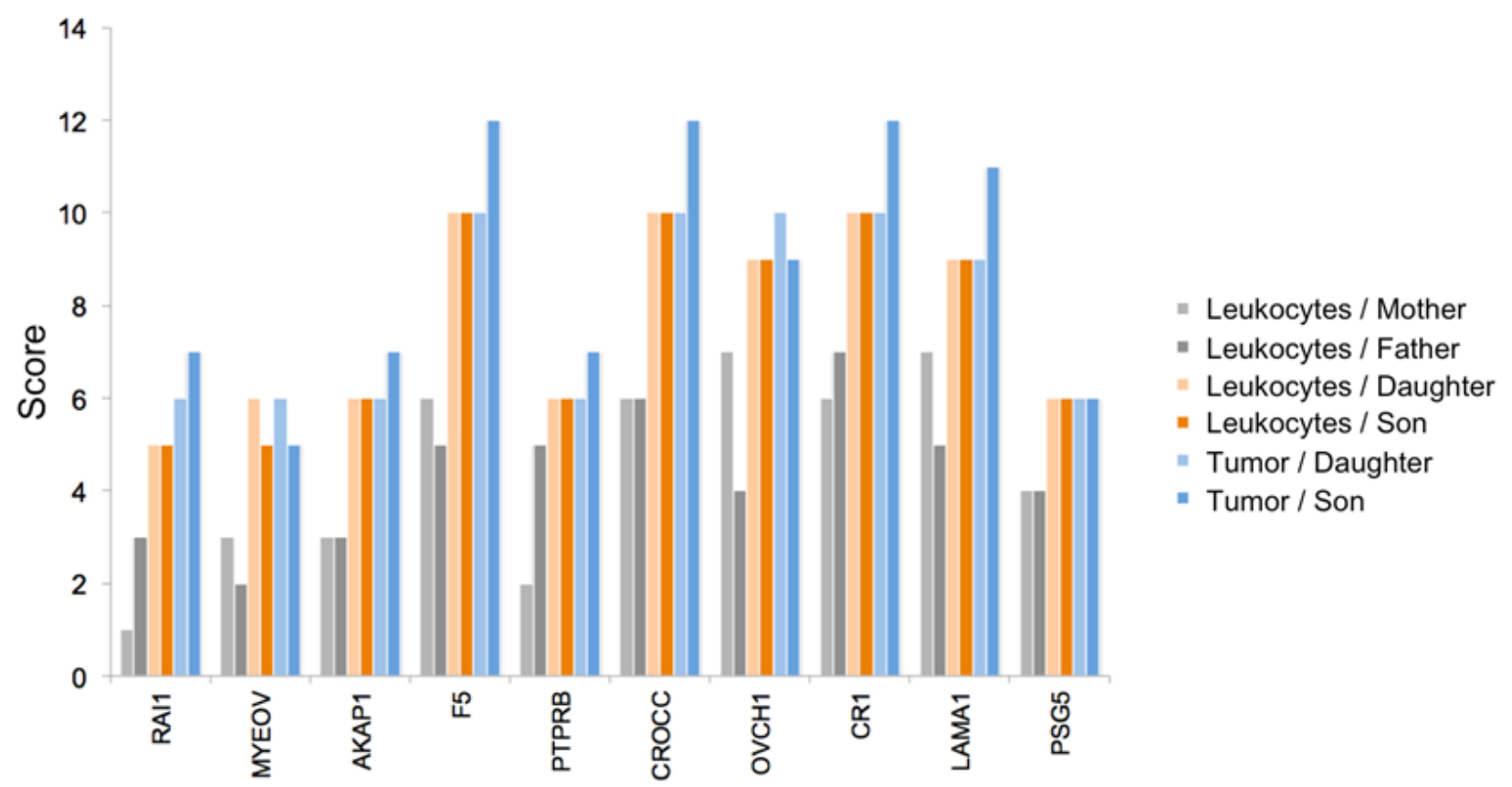

Figure 2: Genes with SNV accumulation. The 6 bar charts show for 10 genes how many homozygous and heterozygous variants can be found in the leukocytes of the parents (two leftmost bars per gene), in the leukocytes of the siblings (two middle bars per gene), and in the GBM DNA of the siblings (two right bars per gene). The bar height corresponds to the computed cumulative score. 
Table 1: Overview of the variants that are homozygous in the children's germlines and heterozygous in the parents' germlines

\begin{tabular}{|c|c|c|c|c|c|c|}
\hline Chr & Position & rs ID & REF & ALT & Gene & \# SNVs \\
\hline chr1 & 1334519 & rs114112990 & $\mathrm{G}$ & $\mathrm{C}$ & CCNL2 & 1 \\
\hline chr1 & 1354515 & rs904589 & C & G & ANKRD65 & 1 \\
\hline chr1 & 19181015 & rs34447754 & $\mathrm{G}$ & $\mathrm{C}$ & TAS1R2 & 1 \\
\hline chr1 & 20977000 & rs1043424 & A & $\mathrm{C}$ & PINK1 & 1 \\
\hline chr1 & 168013850 & rs11558511 & $\mathrm{T}$ & $\mathrm{C}$ & DCAF6 & 1 \\
\hline chr1 & 169498975 & rs6030 & $\mathrm{T}$ & $\mathrm{C}$ & \multirow{4}{*}{ F5 } & \multirow{4}{*}{4} \\
\hline chr1 & 169511555 & rs6032 & $\mathrm{T}$ & $\mathrm{C}$ & & \\
\hline chr1 & 169511734 & rs 4525 & $\mathrm{~T}$ & $\mathrm{C}$ & & \\
\hline chr1 & 169511755 & rs 4524 & $\mathrm{~T}$ & $\mathrm{C}$ & & \\
\hline chr1 & 175092707 & rs10798333 & $\mathrm{C}$ & $\mathrm{T}$ & TNN & 1 \\
\hline chr1 & 196642233 & rs800292 & G & $\mathrm{A}$ & $\mathrm{CFH}$ & 1 \\
\hline chr1 & 200635550 & rs3795634 & $\mathrm{T}$ & $\mathrm{C}$ & DDX59 & 1 \\
\hline chr1 & 201166383 & rs4915221 & $\mathrm{G}$ & $\mathrm{A}$ & IGFN1 & 1 \\
\hline chr1 & 203152801 & rs880633 & $\mathrm{T}$ & $\mathrm{C}$ & CHI3L1 & 1 \\
\hline chr1 & 207753621 & rs2274567 & $\mathrm{A}$ & $\mathrm{G}$ & \multirow{3}{*}{ CR1 } & \multirow{3}{*}{3} \\
\hline chr1 & 207782931 & rs6691117 & $\mathrm{A}$ & $\mathrm{G}$ & & \\
\hline chr1 & 207790088 & rs3811381 & $\mathrm{C}$ & $\mathrm{G}$ & & \\
\hline chr1 & 247615261 & NA & GA & $\mathrm{G}$ & OR2B11 & 1 \\
\hline chr1 & 248020556 & rs11204523 & $\mathrm{G}$ & $\mathrm{C}$ & TRIM58 & 1 \\
\hline chr2 & 10262920 & rs1130609 & $\mathrm{T}$ & $\mathrm{G}$ & RRM2 & 1 \\
\hline chr2 & 71212129 & rs3796100 & $\mathrm{A}$ & $\mathrm{T}$ & \multirow{2}{*}{ ANKRD53 } & \multirow{2}{*}{2} \\
\hline chr2 & 71212405 & rs61732279 & $\mathrm{T}$ & $\mathrm{C}$ & & \\
\hline chr2 & 85622059 & rs6886 & $\mathrm{T}$ & $\mathrm{C}$ & CAPG & 1 \\
\hline chr2 & 86400824 & rs1050301 & $\mathrm{G}$ & $\mathrm{A}$ & IMMT & 1 \\
\hline chr2 & 88472791 & rs4129190 & $\mathrm{G}$ & $\mathrm{A}$ & THNSL2 & 1 \\
\hline chr2 & 209190632 & rs999890 & $\mathrm{T}$ & G & PIKFYVE & 1 \\
\hline chr2 & 228102723 & rs13424243 & $G$ & $\mathrm{C}$ & COL4A3 & 1 \\
\hline chr3 & 4508742 & rs2819590 & C & $\mathrm{T}$ & SUMF1 & 1 \\
\hline chr5 & 122718736 & rs6595440 & $\mathrm{G}$ & $\mathrm{C}$ & CEP120 & 1 \\
\hline chr5 & 141059158 & rs1031904 & C & G & ARAP3 & 1 \\
\hline chr5 & 149001551 & rs4629585 & $\mathrm{A}$ & $\mathrm{C}$ & ARHGEF37 & 1 \\
\hline chr5 & 149772280 & rs1136103 & $\mathrm{C}$ & $\mathrm{G}$ & TCOF1 & 1 \\
\hline chr5 & 150886882 & rs1105168 & $\mathrm{G}$ & $\mathrm{A}$ & FAT2 & 1 \\
\hline chr5 & 180582604 & rs2546423 & $\mathrm{A}$ & $\mathrm{G}$ & OR2V2 & 1 \\
\hline chr6 & 12124587 & rs2228212 & $\mathrm{C}$ & $\mathrm{G}$ & HIVEP1 & 1 \\
\hline chr7 & 6026988 & rs1805321 & $\mathrm{G}$ & $\mathrm{A}$ & PMS2 & 1 \\
\hline chr7 & 87564497 & rs2279542 & C & $\mathrm{G}$ & ADAM22 & 1 \\
\hline chr7 & 88424115 & rs2373396 & $\mathrm{C}$ & $\mathrm{G}$ & C7orf62 & 1 \\
\hline chr8 & 72975801 & rs7819749 & $\mathrm{T}$ & $\mathrm{G}$ & TRPA1 & 1 \\
\hline chr8 & 133975283 & rs2069561 & $\mathrm{G}$ & $\mathrm{A}$ & $\mathrm{TG}$ & 1 \\
\hline chr11 & 3681519 & rs2280134 & $\mathrm{T}$ & $\mathrm{C}$ & ART1 & 1 \\
\hline chr11 & 5718517 & rs7935564 & G & $\mathrm{A}$ & TRIM22 & 1 \\
\hline
\end{tabular}




\begin{tabular}{|c|c|c|c|c|c|c|}
\hline chr11 & 18743180 & rs10832975 & $\mathrm{C}$ & $\mathrm{G}$ & IGSF22 & 1 \\
\hline chr11 & 60776209 & rs11230563 & $\mathrm{C}$ & $\mathrm{T}$ & CD6 & 1 \\
\hline chr11 & 60893235 & rs2229177 & $\mathrm{C}$ & $\mathrm{T}$ & CD5 & 1 \\
\hline chr11 & 62863518 & rs7113279 & $\mathrm{A}$ & $\mathrm{G}$ & SLC22A24 & 1 \\
\hline chr11 & 66083129 & rs3741367 & $\mathrm{T}$ & $\mathrm{C}$ & CD248 & 1 \\
\hline chr11 & 69063393 & rs7103126 & $\mathrm{T}$ & $\mathrm{C}$ & MYEOV & 1 \\
\hline chr11 & 93457532 & rs78544176 & $\mathrm{C}$ & $\mathrm{G}$ & KIAA1731 & 1 \\
\hline chr12 & 18435452 & rs11044004 & $\mathrm{C}$ & $\mathrm{T}$ & PIK3C2G & 1 \\
\hline $\operatorname{chr} 12$ & 25243115 & rs1908946 & $\mathrm{G}$ & $\mathrm{C}$ & LRMP & 1 \\
\hline $\operatorname{chr} 12$ & 29604392 & rs1347570 & $\mathrm{C}$ & $\mathrm{G}$ & OVCH1 & 1 \\
\hline chr14 & 21500121 & rs9624 & $\mathrm{G}$ & $\mathrm{T}$ & TPPP2 & 1 \\
\hline chr14 & 21796784 & rs3748361 & $\mathrm{G}$ & $\mathrm{C}$ & RPGRIP1 & 1 \\
\hline chr14 & 76156609 & rs2303345 & $\mathrm{C}$ & $\mathrm{T}$ & TTLL5 & 1 \\
\hline chr14 & 88651962 & rs 17762463 & $\mathrm{C}$ & $\mathrm{T}$ & KCNK10 & 1 \\
\hline chr14 & 91636532 & rs4900072 & $\mathrm{C}$ & $\mathrm{T}$ & C14orf159 & 1 \\
\hline chr15 & 78466127 & rs2304824 & $\mathrm{T}$ & $\mathrm{C}$ & ACSBG1 & 1 \\
\hline chr15 & 89398407 & rs3743398 & $\mathrm{C}$ & $\mathrm{T}$ & ACAN & 1 \\
\hline chr15 & 90126121 & rs 10775247 & $\mathrm{C}$ & $\mathrm{T}$ & \multirow{2}{*}{ C15orf42 } & \multirow{2}{*}{2} \\
\hline $\operatorname{chr} 15$ & 90128966 & rs11629584 & $\mathrm{C}$ & $\mathrm{T}$ & & \\
\hline chr15 & 90174824 & rs 12900805 & $\mathrm{C}$ & $\mathrm{T}$ & \multirow{2}{*}{ KIF7 } & \multirow{2}{*}{2} \\
\hline chr15 & 90176073 & rs3803530 & $\mathrm{C}$ & A & & \\
\hline chr16 & 71483497 & rs72795864 & $\mathrm{C}$ & $\mathrm{G}$ & ZNF23 & 1 \\
\hline chr16 & 88504850 & rs1105066 & $\mathrm{G}$ & $\mathrm{C}$ & ZNF469 & 1 \\
\hline chr16 & 89350038 & rs2279348 & $\mathrm{G}$ & $\mathrm{A}$ & ANKRD11 & 1 \\
\hline $\operatorname{chr} 17$ & 37814080 & rs1877031 & $\mathrm{G}$ & A & STARD3 & 1 \\
\hline $\operatorname{chr} 17$ & 37879588 & rs1136201 & $\mathrm{A}$ & $\mathrm{G}$ & \multirow{2}{*}{ ERBB2 } & \multirow{2}{*}{2} \\
\hline $\operatorname{chr} 17$ & 37884037 & rs61552325 & $\mathrm{C}$ & $\mathrm{G}$ & & \\
\hline $\operatorname{chr} 17$ & 55182878 & rs17761023 & $\mathrm{C}$ & $\mathrm{T}$ & \multirow{3}{*}{ AKAP1 } & \multirow{3}{*}{3} \\
\hline chr17 & 55183792 & rs35359994 & $\mathrm{G}$ & $\mathrm{A}$ & & \\
\hline $\operatorname{chr} 17$ & 55183813 & rs 34535433 & $\mathrm{~A}$ & $\mathrm{G}$ & & \\
\hline $\operatorname{chr} 17$ & 66538239 & rs2302234 & $\mathrm{G}$ & $\mathrm{T}$ & FAM20A & 1 \\
\hline $\operatorname{chr} 17$ & 67125840 & rs4968839 & $\mathrm{C}$ & $\mathrm{T}$ & ABCA6 & 1 \\
\hline $\operatorname{chr} 17$ & 67178316 & rs4968849 & $\mathrm{A}$ & $\mathrm{G}$ & \multirow{2}{*}{ ABCA10 } & \multirow{2}{*}{2} \\
\hline $\operatorname{chr} 17$ & 67212423 & rs9909216 & $\mathrm{G}$ & $\mathrm{A}$ & & \\
\hline chr17 & 76528790 & rs11651537 & $\mathrm{A}$ & $\mathrm{G}$ & DNAH17 & 1 \\
\hline chr18 & 6997818 & rs12961939 & $\mathrm{A}$ & $\mathrm{C}$ & LAMA1 & 1 \\
\hline chr21 & 37617630 & rs4817788 & $\mathrm{T}$ & $\mathrm{G}$ & DOPEY2 & 1 \\
\hline chr22 & 26222454 & rs9624909 & $\mathrm{C}$ & $\mathrm{T}$ & MYO18B & 1 \\
\hline $\operatorname{chr} 22$ & 29885016 & rs59371099 & $\mathrm{G}$ & $\mathrm{A}$ & NEFH & 1 \\
\hline chr22 & 30762140 & rs740223 & $\mathrm{G}$ & $\mathrm{A}$ & CCDC157 & 1 \\
\hline $\operatorname{chr} 22$ & 30776095 & rs5749088 & $\mathrm{C}$ & $\mathrm{T}$ & RNF215 & 1 \\
\hline $\operatorname{chr} 22$ & 31491295 & rs3205187 & $\mathrm{G}$ & $\mathrm{C}$ & SMTN & 1 \\
\hline chr22 & 36537763 & rs61741884 & $\mathrm{C}$ & $T$ & $\mathrm{APOL3}$ & 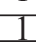 \\
\hline
\end{tabular}


Table 2: SNVs in tumor DNA of the siblings that were not present in their leukocyte DNA

\begin{tabular}{|c|c|c|c|c|c|}
\hline CHROM & POS & rs ID & REF & ALT & Gene \\
\hline $\operatorname{chr} 1$ & 3389970 & . & $\mathrm{G}$ & A & ARHGEF16 \\
\hline chr2 & 74763923 & . & G & GC & LOXL3 \\
\hline chr6 & 151815279 & rs199768731 & $\mathrm{A}$ & C & CCDC170 \\
\hline chr6 & 157528243 & . & $\mathrm{C}$ & $\mathrm{T}$ & ARID1B \\
\hline chr7 & 22184668 & . & $\mathrm{G}$ & $\mathrm{A}$ & RAPGEF5 \\
\hline chr11 & 89883678 & . & G & A & NAALAD2 \\
\hline $\operatorname{chr} 15$ & 75982085 & rs79463888 & $\mathrm{C}$ & $\mathrm{T}$ & CSPG4 \\
\hline $\operatorname{chr} 16$ & 3025782 & . & $\mathrm{G}$ & A & PKMYT1 \\
\hline $\operatorname{chr} 16$ & 30750387 & . & $\mathrm{G}$ & A & SRCAP \\
\hline $\operatorname{chr} 16$ & 85682289 & . & A & $\mathrm{AC}$ & KIAA0182 \\
\hline $\operatorname{chr} 17$ & 7577121 & rs121913343 & G & A & TP53 \\
\hline $\operatorname{chr} 17$ & 77111776 & . & C & $\mathrm{G}$ & RBFOX3 \\
\hline $\operatorname{chr} 19$ & 6374295 & . & G & A & ALKBH7 \\
\hline chr19 & 54649413 & . & G & A & CNOT3 \\
\hline $\operatorname{chr} 20$ & 60775922 & rs35693261 & C & $\mathrm{T}$ & GTPBP5 \\
\hline
\end{tabular}

of 1 and homozygous variants a score of 2 . The score of a gene corresponds to the sum over all positions. To find the most affected genes and to trade off between sensitivity and specificity we carried out three filter steps: First, all genes with a score below 5 in children were excluded, leaving the more frequently affected genes. Second, the average score of children has to be at least $150 \%$ of the average score of parents, leaving the genes where children are more affected. This analysis however also contained genes where one parent was as affected as one of the children. Third, scores of both children combined had to be higher than the scores of both parents combined. The filtering finally resulted in a set of 10 genes that are summarized together with their scores in Figure 2. Supplemental Table 1 summarizes all high scoring genes. In Figure 2 we show for each gene 6 bars representing the scores of both parents' leukocyte DNA, the scores of the siblings' leukocyte DNA samples and the scores of two GBM DNA samples. Out of the 10 genes, 6 have already been discovered in the initial analysis of homozygous variants in the siblings, namely MYEOV, AKAP1, F5, OVCH1, CR1 and LAMA1. Beyond these, we detected RAI1, PTPRB, CROCC and PSG5.

The variants leading to these scores are exemplarily shown for CROCC and PTPRB in Figure 3, for the remaining genes respective material is available in Supplemental Table 2. In this figure it can be seen that the children in both cases have all mutations of both parents, indicating a potential cumulative effect.

Since the daughter developed four different tumors, specific genetic factors may have contributed to the tumorigenesis in the daughter as compared to the son. We carried out the same scoring as described above, but with focus on the sex related differences. We specifically searched for genes that were more affected in the daughter as compared to the son by calculating the difference of the scores (Figure 4). For the gene XIRP2 we obtained scores of 12 and 13 for the mother and the father, respectively, a score of 25 for the daughter and a score of 0 for the son (Figure 5). For the gene PCNT we found a score of 20 and 12 for mother and father, respectively, a score of 21 for the daughter and of 13 for the son. Likewise we found for the daughter an elevated score for the G-protein coupled receptor 98 (GPR98). For this gene, the parents' scores were 15 and 11, the score of the son 13 and the score of the daughter 21 (Supplemental Table 1 provides a summary). The SNV accumulation for the XIRP2 locus with RS ID is given in Figure 5. The according information for other relevant genes is given in Supplemental Table 2. For some genes we also found scores that were elevated for the son as compared to his sister (see Supplemental Tables 1 and 2).

\section{Statistical enrichment analysis}

After interpreting single variants and accumulation on genes we carried out a statistical enrichment analysis to improve the understanding of the variants and affected genes on a systematic level. Specifically, we applied our Gene Set Analysis Tool GeneTrail, as described in the Materials and Methods section. First, we asked whether the 73 genes carrying at least one homozygous variant in the children that are heterozygous in the parents are clustered with respect to the genomic localization. On the highest level we discovered significant clustering on three chromosomes, chromosome 1 (15 genes, adjusted p-value of $\left.2.2^{*} 10^{-4}\right)$, chromosome 22 ( 7 genes, adjusted 
p-value of $\left.7.1 * 10^{-4}\right)$ and chromosome 11 (10 genes, adjusted p-value of $1.9 * 10^{-3}$ ). Altogether, 32 of all 75 genes have been localized on these three chromosomes. More precisely, we discovered significant enrichment of 12 chromosomal bands. The highest accumulation was calculated for chr22 q12.2 (4 genes, adjusted p-value of $1.6^{*} 10^{-4}$ ) and chr1 p36.33 (3 genes, adjusted p-value of $\left.3.5^{*} 10^{-3}\right)$. All significant genomic clusters are available in the Supplemental Table 3.

To identify enriched regulatory/metabolic pathways for the genes we applied a KEGG pathway analysis. Here, we found 3 significant pathways that contain at least three affected genes: focal adhesion (4 genes, adjusted p-value of $\left.9.8^{*} 10^{-3}\right)$, ECM-receptor interaction (3 genes, adjusted p-value of $\left.9.8 * 10^{-3}\right)$, and complement and coagulation cascades ( 3 genes, adjusted p-value of $\left.9.8^{*} 10^{-3}\right)$. In the first two paths the genes TNN, LAMA1, ERBB2 and COL4A3 were found, in the complement and conjugate cascades CFH, CR1 and F5. Remarkably, CR1 and F5 belong to the genes with most variants overall (see Table $1)$.

The KEGG pathway analysis has two essential drawbacks: pathways are considered as separate entities and show partially a high redundancy. We thus searched for functional interrelations between the affected genes without paying attention to the pre-defined pathways annotated by KEGG. Specifically, we used the STRING database [19] to extract interactions between all genes. Altogether, 100 such interactions have been found by adding 20 additional partner genes. The interactions together with all scores are provided in Supplemental Table 4. The core connected component generated by STRING has been visualized by Cytoscape [20]. To indicate how much the respective parts are affected, the fold change of scores for each gene as computed in the last paragraph has been used to color the nodes. As indicated in Figure 6, several genes including e.g. F5, LAMA1, $E R B B 2$ or $S T A R D 3$ seems to be in proximity to genes of the EGF/EGFR signaling cascade, which is known to be important in glioma [21].

Former studies revealed chitinase 3-like protein 1 (CHI3LI) to be highly expressed in human glioma tissue and hence, to play an important role in the regulation of malignant transformation and local invasiveness

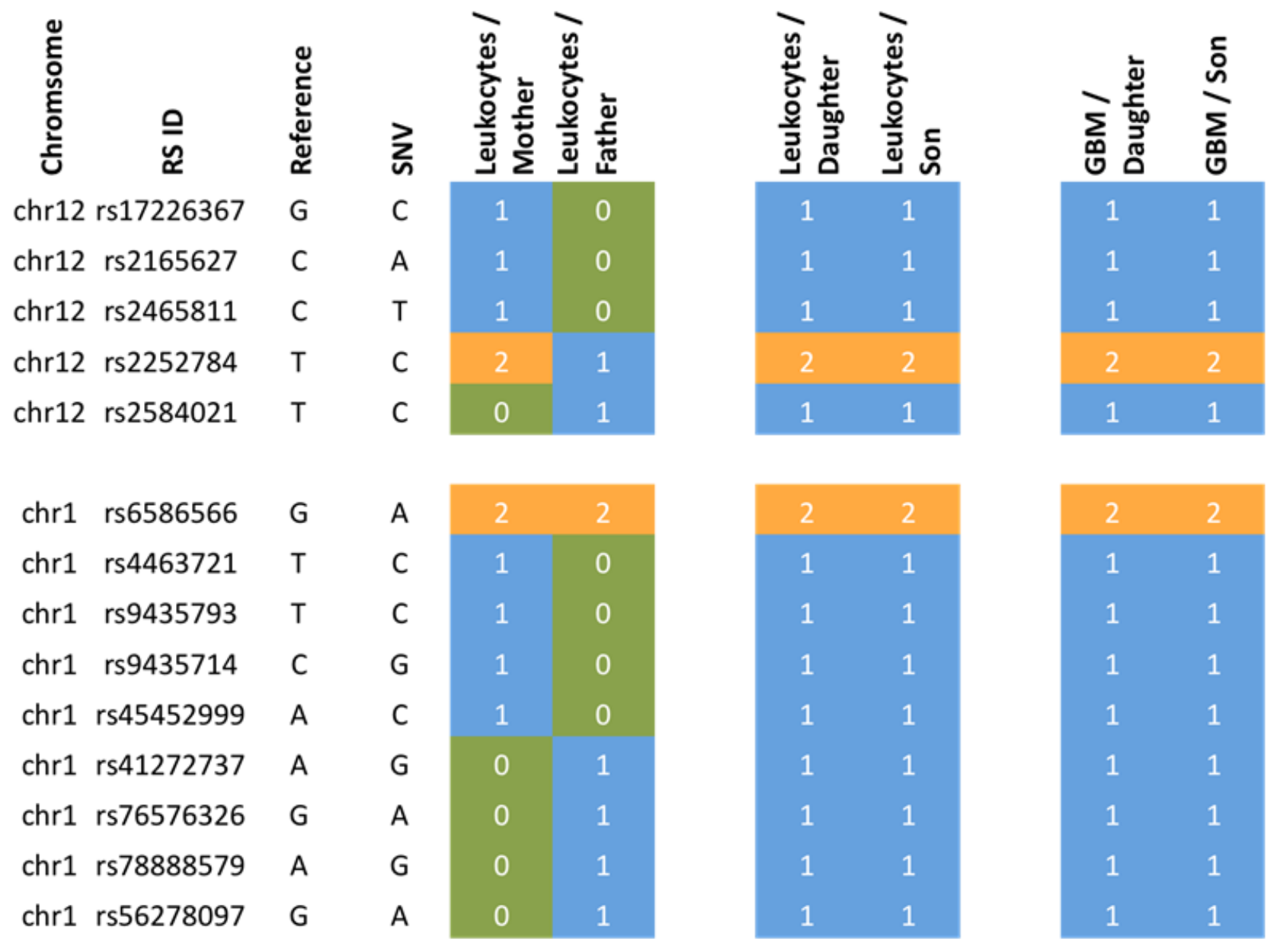

Figure 3: Accumulation of variants from father and mother in the siblings. Blue colored genotypes are heterozygous ("1"), green colored genotypes wild type ("0") and orange genotypes homozygous variants ("2"). The top part represents the gene PTPRB, the bottom part CROCC. 


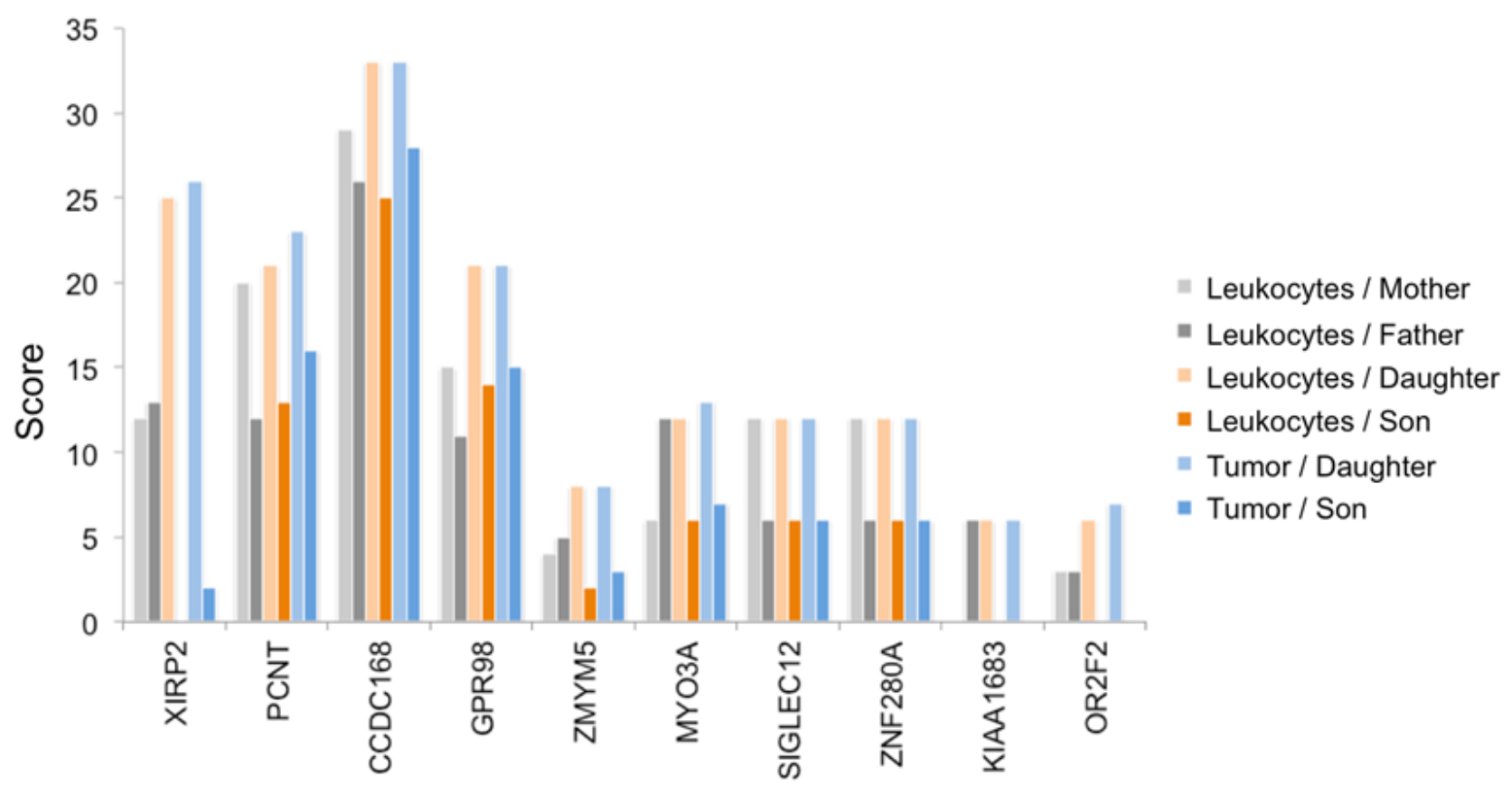

Figure 4: Genes with SNV accumulation in the daughter. The 6 bar charts show for 10 genes that are substantially more affected in the daughter as compared to the son how many homozygous and heterozygous variants can be found in leukocytes of parents (two leftmost bars per gene), leukocytes of siblings (two middle bars per gene), and GBM DNA of the siblings (two right bars per gene). The bar height corresponds to the computed cumulative score.

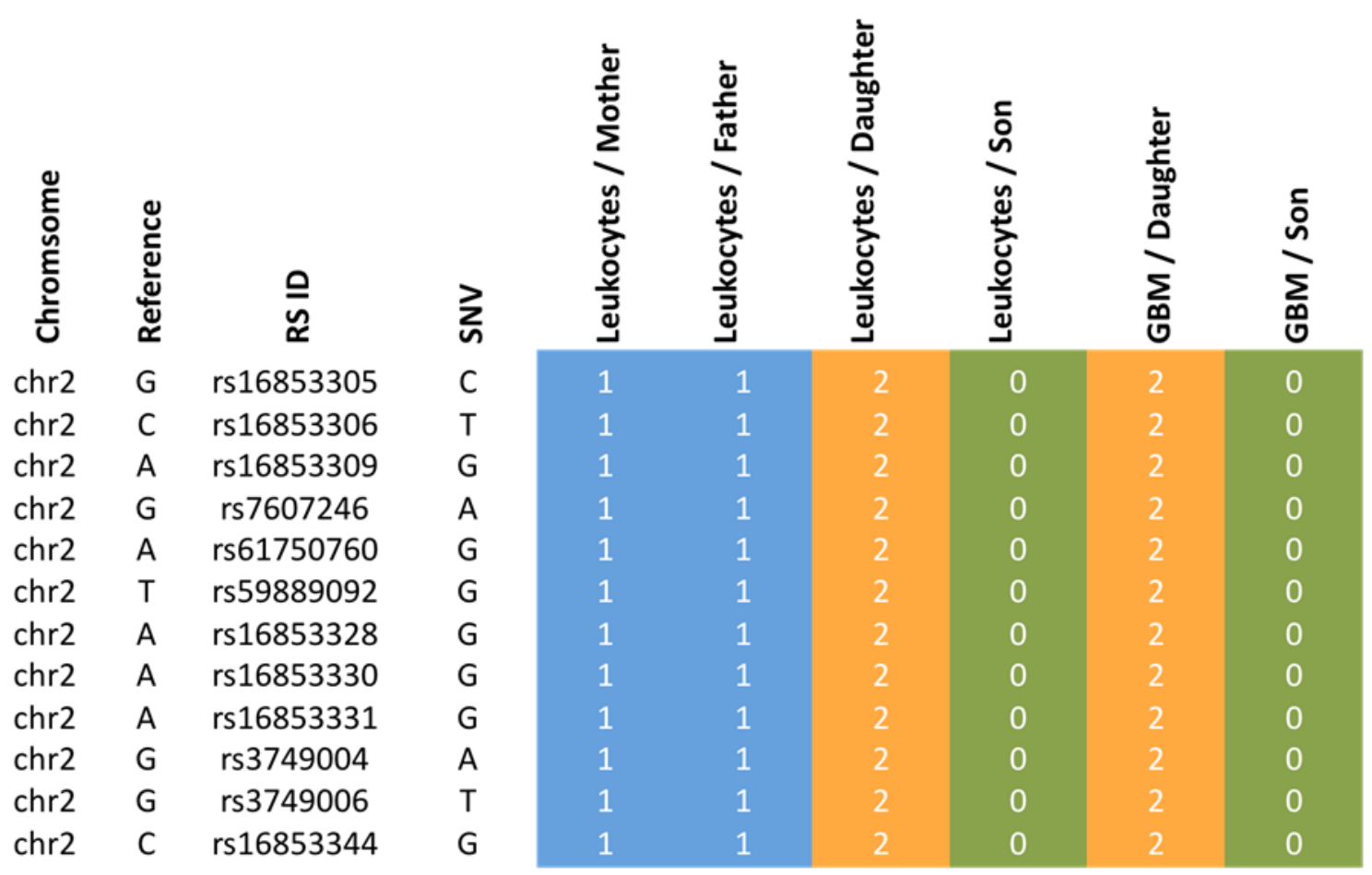

Figure 5: Accumulation of variants for the XIRP2 gene of the daughter. Blue colored genotypes are heterozygous ("1"), green colored genotypes wild type ("0") and orange genotypes homozygous variants ("2"). 
in gliomas [22]. Figure 7 displays the 3D structure of CHI3LI with highlighted mutations detected within our data set. The representation was created via the molecular modeling visualization tool BALLView [23].

\section{Mutations in tumor DNA not present in leukocytes}

So far we mainly focused on germline mutations. To gain further insights into the genetic alterations

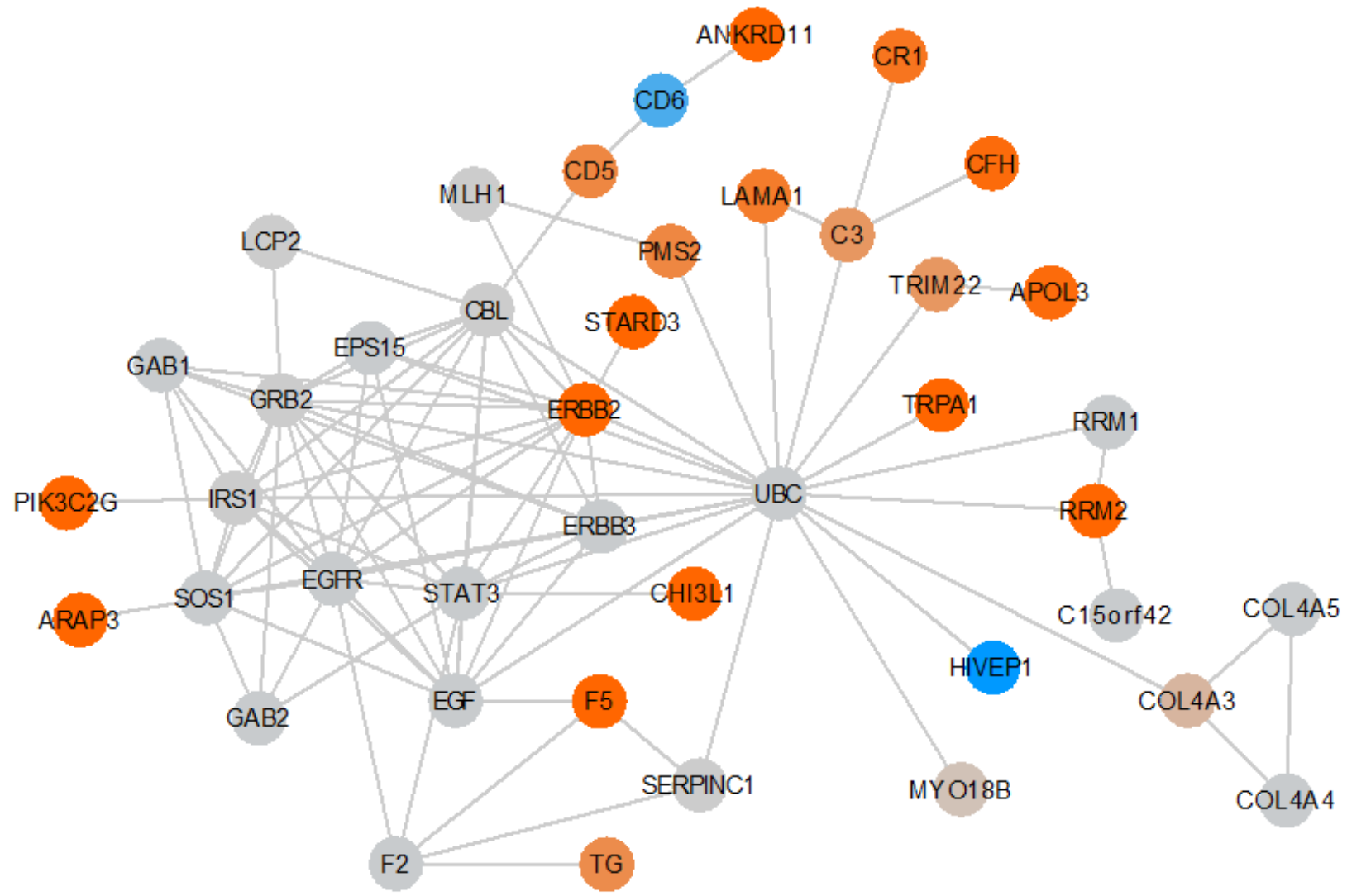

Figure 6: Key GBM network. The graphic shows the core-connected component of the interaction network derived from the STRING database. Nodes are colored with respect to the fold change of the score in children and parents. Genes with elevated scores are indicated in orange. Increased color intensity indicates an increased SNV accumulation in the respective gene. Genes with low scores are indicated in blue. Genes indicated in gray are not scored but added by STRING to the network.

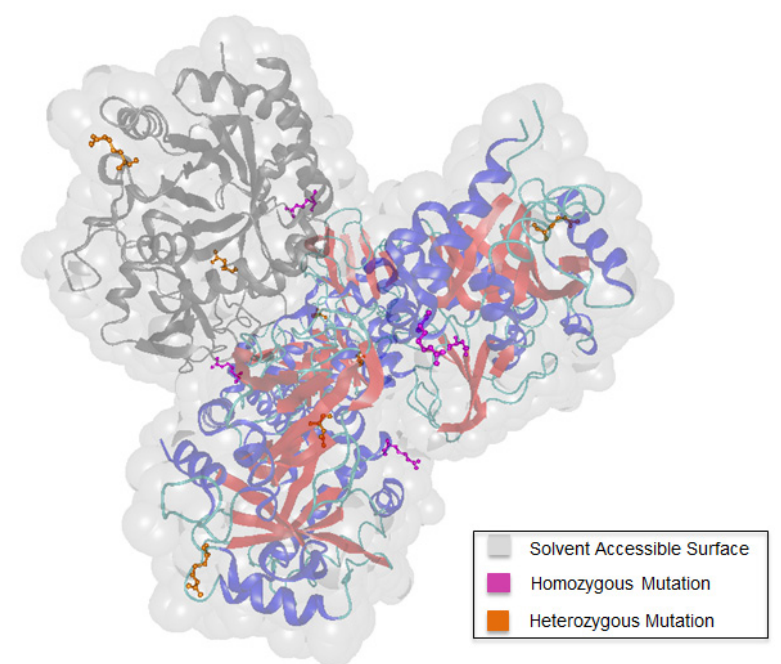

Figure 7: 3D structure of chitinase-3-like protein 1 (CHI3L1). The four chains of CHI3L1 are colored according to their secondary structure elements. To highlight the distribution of the detected mutations within one chain, chain $\mathrm{C}$ is colored in grey. We differentiate between homozygous (pink) and heterozygous (orange) mutations. 
of the tumor during its development, we performed a second analysis filtering those variants that became homozygous in tumor while being heterozygous or wildtype in the children's leukocyte DNA. Just one single variant showed the required genotype composition in leukocyte and tumor DNA, a frameshift mutation in the gene RAI1. This gene has already been discovered to be more affected in the siblings' leukocyte DNA as compared to parental leukocytes. Next, we searched for variants that were homozygous wild type in leukocyte DNA but heterozygous in tumor DNA of both siblings. Altogether we discovered 15 such variants that are summarized in Table 2. Among them we found variations in genes TP53 (rs121913343), LOXL3 (chr2:74763923, G>GC), CSPG4 (rs79463888), and ARID1B (chr6:157528243, C>T).

\section{DISCUSSION}

Familial exome sequencing is a valuable tool to unravel associations between the genotype and pathogenic processes. Respective studies are not only relevant for Mendelian disorders but can also be applied to diseases with complex hereditary factors. In this study, we described the whole exome analysis of a family with two unaffected parents and two siblings suffering of glioblastoma multiforme (GBM) at an early age. Considering the multiple incidences of different carcinoma types in the family pedigree and the unusual early development of GBM in both children, we assumed a genetic predisposition promoting the GBM development. To confirm this hypothesis, we concentrated especially on non-synonymous variants that became newly homozygous in both children while being heterozygous in both parents. In total, we detected 85 such variants in 73 different genes, containing previously known key players in GBM tumorigenesis such as PMS2. To reflect the complexity and molecular heterogeneity of GBM we calculated accumulation of variants in genes and performed a pathway and network analysis to get an overview on the interplay of the identified genes.

In addition to the accumulation of variants in genes we also performed statistical enrichment analysis. The results of our network analysis present several key players that seem to be relevant for the tumorigenesis of GBM. Polymorphisms in CR1 (CD35) are discussed to play a role in cerebral amyloid angiopathy, which is a leading cause in intracerebral hemorrhage [24] and might even be associated with the risk of Alzheimer's disease [25]. Notably, the factor V Leiden mutation [26], which is a common risk factor for thrombophilia, is a known variant of F5 that is a member of the complement and coagulation cascades like CR1. Although, we did not find the factor $\mathrm{V}$ Leiden mutation, the $F 5$ gene accumulated the most new non-synonymous homozygous variants in both children. These homozygous variants might also impact the F5 protein function. The interplay of intracerebral hemorrhage and thrombophilia may cause microenvironments of oxygen deprivation / hypoxia promoting the development of GBM. Hypoxia has been described as an important pathogenic factor in GBM and other malignancies [27, 28].

Another interesting group of genes are $T N N$, $L A M A 1$, and $E R B B 2$, where all three are involved in focal adhesion, and the first two additionally in the ECMreceptor interaction pathway. Those two pathways are crucial for the migration of cells and for the maintenance of tissue architecture [29]. Furthermore, these processes contribute to tumor invasion of the surrounding normal tissues. Especially ERBB2, being the dimerization partner of EGFR, has previously been associated with glioma risk. Previous SNP analysis of glioma patients indicated $E R B B 2$ as a low penetrance gene associated with risk of glioblastoma development [30]. The SNP rs1058808 in ERBB2 mentioned in the publication of Andersson et al. [30] corresponds to the variant that we described, which became homozygous in both siblings. We also found a heterozygous variant in EGFR (chr7:55229255, rs2227983, G>A) for father and son. The increase of the non-synonymous homozygous SNV load in both children's leukocyte DNA in genes related to the EGFR signaling cascade likely contributes to an increased risk/ predisposition for GBM in both siblings.

In the neighborhood of these genes we discovered a strong association with GBM for the gene PMS2, an important gene for DNA repair. PMS2 has been demonstrated to be important for GBM in various studies $[31,32]$. Most interestingly, Walter and co-workers describe the case of a 13-year-old child presented with three simultaneous malignancies, including GBM. Here, the genetic analysis also revealed a homozygous mutation in the PMS2 gene [33].

Remarkably we also discovered a mutation in TP53 in GBM DNA of siblings, which was not present in leukocytes. Altogether, 15 genes showed respective genotype composition, including $A R I D 1 B$, a component of the SWI/SNF chromatin remodeling complex also relevant for the chromatin architecture $[34,35]$. Expression of the transmembrane proteoglycan CSPG4 has been associated with melanoma formation and takes place in a number of normal tissues throughout development [36]. Expression of CSPG4 seems to correlate with poor prognosis in several cancer types including GBM [37]. LOXL3 encodes a member of the lysyl oxidase gene family. Members of this family are responsible for the development of crosslinks in extracellular matrix proteins, such as collagens and elastin [38], and may play a role in tumor progression [39].

In addition, the development of tumors in both siblings at an early age indicates that some of the genes, which have been identified in our SNP analysis but not yet been associated with GBM, may also play a role the development of GBM. 
Since the daughter was diagnosed with four different tumors, we also investigated gender specific changes. For the daughter we found an accumulation of variants for several genes including XIRP2, PCNT, CCDC168 and GPR98, the latter of which was reported to be associated with GBM survival by alternative exon usage [40]. Notably, exon level analysis recently defined several new GC-regulated transcript variants including GPR98 in childhood acute lymphoblastic leukemia [41]. The gene XIRP2 that was most affected in our analysis, was reported to be expressed mainly in striated muscles [42], but it has not yet been connected to tumor development.

In a previous study we searched for SNPs in glioblastoma samples by targeted re-sequencing [43]. Interestingly, several of the identified genes including MDM1, PAXIP1, PARP1, SART1 and B4GALNT1, showed also mutations in the present study. These genes were, however, not affected in both children but predominantly in the son.

\section{CONCLUSIONS}

In summary, we have identified a group of genes all of which show an accumulation of homozygous or heterozygous germline variants in both siblings. Especially the daughter, who was diagnosed with four different tumors, seems to be strongly affected. By using prediction tools for regulatory pathways and functional interaction information we showed that these genes are likely involved in specific pathways including focal adhesion and ECM receptor interaction, which are known to be relevant for GBM development. The unfortunate accumulation of homozygous variants in both siblings might have promoted the early onset of GBM in both children with both carrier parents unaffected.

\section{MATERIAL AND METHODS}

\section{Samples}

We collected Glioblastoma multiforme (GBM) tumor samples from two children, brother and sister, that came down with the diagnosis at the age of 10 and 12 years. The sister suffered from a supratentorial GBM (WHO grade IV) and from a pilocytic infratentorial astrocytoma (WHO grade I) and the brother from a GBM (WHO grade IV), based on the right ventricular trigonum with thalamic infiltration of the dorsal ventricular structures, of the septum pellucidum and the midbrain. The sister also developed a common acute lymphatic leukemia (cALL) 8 months after the diagnosis of GBM as well as a diffuse pontine glioma at the age of 15 years. We also collected whole blood from the children in lithium heparin plasma tubes. Both parents are healthy without any history of brain tumor or cancer disease. In the history of the family, we found from the paternal side, two cases of meningioma that did not require any treatment, one case of ovarian carcinoma and one case of colon carcinoma. From the maternal side, we found one case of prostate carcinoma and one case of melanoma. To determine whether the GBMs of the children were caused by a genetic anomaly inherited from the parents, we also collected whole blood in lithium heparin tubes from the parents to analyze differences and similarities between the exomes of the leukocytes from the children and the leukocytes from the parents additional to the comparison of the exomes of both children's tumors. All samples were obtained with parents' informed consent and the local ethic committee ("Ethik-Kommission der Ärztekammer des Saarlandes", No. 67/06) approved the study. The isolation of genomic DNA from the GBM tumor samples of both children and from the parents' and children's leukocytes was performed according to standard protocols. For tumor DNA isolation, five $10 \mu \mathrm{m}$ tumor slices have been used. Adjacent slices have been histologically confirmed to have tumor cell content above $90 \%$.

\section{Exome sequencing and bioinformatic analyses}

We performed whole exome capture and sequencing for a total of six samples consisting of blood samples of all four individuals, the healthy parents and the two affected children, as well as DNA from the glioblastoma of the latter two. The six samples were enriched using Illumina'sTruSeq Exome Enrichment Kit, targeting $62 \mathrm{Mb}$ of exomic sequence, including 5'-UTR, 3'UTR, microRNA, and other non-coding RNA. Exome sequencing of $2 \times 100 \mathrm{bp}$ paired-end reads was performed for all six samples together on one lane of an Illumina HiSeq2000. The reads were mapped against the human reference genome build hg19 using BWA [12], followed by the removal of PCR duplicates with Picard (http:// picard.sourceforge.net).

Following the Genome Analysis Toolkit (GATK) Best Practices v3 guideline, we used the GATK 1.6-11 [13] for further processing the mapped reads and for SNP and indel calling. In brief, we computed the intervals for local realignment and performed the realignment to reduce false positive variant calls around indels. After fixing the mate information for paired-end reads, we performed the GATK quality score recalibration steps. Finally, the SNPs/ indels were called for the six input samples simultaneously with the GATK UnifiedGenotyper using the following default parameters: -stand_call_conf 50.0 -stand_emit_ conf 10.0. After that we applied the proposed filtering for small sample exome data using VariantFiltration.

For annotating the genes and class of SNPs/indels, we used ANNOVAR [14]. Next, we applied different filters. In order to detect potential relevant SNVs we identified variants where the parents were heterozygous 
and both siblings homozygous for the variant. Since single variants may not suffice to represent the heterogeneous genetics of GBM we searched for an accumulation of effects. First, clustering of affected genes on pathways and genomics positions was investigated. Here, the corresponding genes identified in the previous step were analyzed with respect to their enrichment in KEGG pathways $[15,16]$ and chromosome bands with GeneTrail [17]. The computed p-values for these categories were FDR adjusted [18] and considered significant if smaller than 0.05 . Beyond the pathway analysis we also searched for accumulation of variants in genes, i.e. cases where both parents carry homozygous or heterozygous variants that finally accumulate in both siblings.

To construct a complex network we used STRING using the standard parameters, i.e. we included Neighborhood, Gene Fusion, Co-occurrence, Coexpression, Experiments, Databases and Textmining [19]. To augment the network we used twice the "add" option and thereby added 20 additional partners. The resulting networks with scores are provided in the Supplemental Material of this manuscript.

\section{ACKNOWLEDGMENTS}

\section{Conflicts of interest} interests.

The author(s) declare that they have no conflicts of

\section{REFERENCES}

1. Stupp R, van den Bent MJ and Hegi ME. Optimal role of temozolomide in the treatment of malignant gliomas. Current neurology and neuroscience reports. 2005; 5(3):198-206.

2. Ohgaki $\mathrm{H}$ and Kleihues P. Genetic pathways to primary and secondary glioblastoma. The American journal of pathology. 2007; 170(5):1445-1453.

3. Haque T, Faury D, Albrecht S, Lopez-Aguilar E, Hauser P, Garami M, Hanzely Z, Bognar L, Del Maestro RF, Atkinson J, Nantel A and Jabado N. Gene expression profiling from formalin-fixed paraffin-embedded tumors of pediatric glioblastoma. Clin Cancer Res. 2007; 13(21):6284-6292.

4. Parsons DW, Jones S, Zhang X, Lin JC-H, Leary RJ, Angenendt P, Mankoo P, Carter H, Siu IM, Gallia GL, Olivi A, McLendon R, Rasheed BA, Keir S, Nikolskaya T, Nikolsky Y, et al. An Integrated Genomic Analysis of Human Glioblastoma Multiforme. Science (New York, NY). 2008; 321(5897).

5. Blumenthal DT and Cannon-Albright LA. Familiality in brain tumors. Neurology. 2008; 71(13):1015-1020.

6. Malmer B, Iselius L, Holmberg E, Collins A, Henriksson
$\mathrm{R}$ and Gronberg H. Genetic epidemiology of glioma. Br J Cancer. 2001; 84(3):429-434.

7. Shete S, Lau CC, Houlston RS, Claus EB, Barnholtz-Sloan J, Lai R, Il'yasova D, Schildkraut J, Sadetzki S, Johansen C, Bernstein JL, Olson SH, Jenkins RB, Yang P, Vick NA, Wrensch M, et al. Genome-Wide High-Density SNP Linkage Search for Glioma Susceptibility Loci: Results from the Gliogene Consortium. Cancer Research. 2011; 71(24):7568-7575.

8. Johnson AM, Zuhlke KA, Plotts C, McDonnell SK, Middha S, Riska SM, Schaid DJ, Thibodeau SN, Douglas JA and Cooney KA. Mutational landscape of candidate genes in familial prostate cancer. The Prostate. 2014; 74(14):13711378.

9. Hanks S, Perdeaux ER, Seal S, Ruark E, Mahamdallie SS, Murray A, Ramsay E, Del Vecchio Duarte S, Zachariou A, de Souza B, Warren-Perry M, Elliott A, Davidson A, Price $\mathrm{H}$, Stiller C, Pritchard-Jones K, et al. Germline mutations in the PAF1 complex gene CTR9 predispose to Wilms tumour. Nat Commun. 2014; 5:4398.

10. Wen H, Kim YC, Snyder C, Xiao F, Fleissner EA, Becirovic D, Luo J, Downs B, Sherman S, Cowan KH, Lynch HT and Wang SM. Family-specific, novel, deleterious germline variants provide a rich resource to identify genetic predispositions for BRCAx familial breast cancer. BMC Cancer. 2014; 14:470.

11. Bai X, Lv H, Zhang F, Liu J, Fan Z, Xu L, Han Y, Chai $\mathrm{R}$, Li $\mathrm{J}$ and Wang $\mathrm{H}$. Identification of a novel missense mutation in the WFS1 gene as a cause of autosomal dominant nonsyndromic sensorineural hearing loss in allfrequencies. American journal of medical genetics Part A. 2014.

12. Li H and Durbin R. Fast and Accurate Short Read Alignment with Burrows-Wheeler Transform. Bioinformatics. 2009; 25(14):1754-1760.

13. McKenna A, Hanna M, Banks E, Sivachenko A, Cibulskis K, Kernytsky A, Garimella K, Altshuler D, Gabriel S, Daly $\mathrm{M}$ and DePristo MA. The Genome Analysis Toolkit: a MapReduce framework for analyzing next-generation DNA sequencing data. Genome Research. 2010; 20(9):12971303.

14. Wang K, Li M and Hakonarson H. ANNOVAR: functional annotation of genetic variants from high-throughput sequencing data. Nucleic Acids Research. 2010; 38(16):e164-e164.

15. Kanehisa M. The KEGG database. Novartis Found Symp. 2002; 247:91-101; discussion 101-103, 119-128, 244-252.

16. Kanehisa M, Goto S, Hattori M, Aoki-Kinoshita KF, Itoh M, Kawashima S, Katayama T, Araki M and Hirakawa M. From genomics to chemical genomics: new developments in KEGG. Nucl Acids Res. 2006; 34(suppl_1):D354-357.

17. Backes C, Keller A, Kuentzer J, Kneissl B, Comtesse N, Elnakady YA, Müller R, Meese E and Lenhof H-P. GeneTrail-advanced gene set enrichment analysis. Nucleic 
Acids Research. 2007; 35(Web Server issue).

18. Benjamini $\mathrm{Y}$ and Hochberg Y. Controlling the false discovery rate: a practical and powerful approach to multiple testing. Journal of the Royal Statistical Society Series B Methodological. 1995; 57(1):289-300.

19. Szklarczyk D, Franceschini A, Kuhn M, Simonovic M, Roth A, Minguez P, Doerks T, Stark M, Muller J, Bork $\mathrm{P}$, Jensen LJ and von Mering C. The STRING database in 2011: functional interaction networks of proteins, globally integrated and scored. Nucleic Acids Research. 2011; 39(Database issue):D561-D568.

20. Shannon P, Markiel A, Ozier O, Baliga NS, Wang JT, Ramage D, Amin N, Schwikowski B and Ideker T. Cytoscape: a software environment for integrated models of biomolecular interaction networks. Genome Research. 2003; 13(11):2498-2504.

21. Paul I, Bhattacharya S, Chatterjee A and Ghosh MK. Current Understanding on EGFR and Wnt/beta-Catenin Signaling in Glioma and Their Possible Crosstalk. Genes \& cancer. 2013; 4(11-12):427-446.

22. Ku BM, Lee YK, Ryu J, Jeong JY, Choi J, Eun KM, Shin HY, Kim DG, Hwang EM, Yoo JC, Park JY, Roh GS, Kim HJ, Cho GJ, Choi WS, Paek SH, et al. CHI3L1 (YKL-40) is expressed in human gliomas and regulates the invasion, growth and survival of glioma cells. International journal of cancer Journal international du cancer. 2011; 128(6):13161326.

23. Moll A, Hildebrandt A, Lenhof HP and Kohlbacher O. BALLView: a tool for research and education in molecular modeling. Bioinformatics. 2006; 22(3):365-366.

24. Biffi A, Shulman JM, Jagiella JM, Cortellini L, Ayres AM, Schwab K, Brown DL, Silliman SL, Selim M, Worrall BB, Meschia JF, Slowik A, Jager PLD, Greenberg SM, Schneider JA, Bennett DA, et al. Genetic variation at CR1 increases risk of cerebral amyloid angiopathy. Neurology. 2012; 78(5):334-341.

25. Lambert J-C, Heath S, Even G, Campion D, Sleegers K, Hiltunen M, Combarros O, Zelenika D, Bullido MJ, Tavernier B, Letenneur L, Bettens K, Berr C, Pasquier F, Fiévet N, Barberger-Gateau P, et al. Genome-wide association study identifies variants at CLU and CR1 associated with Alzheimer's disease. Nature Genetics. 2009; 41(10):1094-1099.

26. Dahlbäck B. The discovery of activated protein $\mathrm{C}$ resistance. Journal of Thrombosis and Haemostasis. 2003; 1(1):3-9.

27. Anand M and Brat DJ. Oncogenic regulation of tissue factor and thrombosis in cancer. Thrombosis Research. 2012; 129, Supplement 1(0):S46-S49.

28. Bar EE. Glioblastoma, Cancer Stem Cells and Hypoxia. Brain Pathology. 2011; 21(2):119-129.

29. Nagano M, Hoshino D, Koshikawa N, Akizawa T and Seiki M. Turnover of Focal Adhesions and Cancer Cell Migration. International Journal of Cell Biology. 2012; 2012:1-10.
30. Andersson U, Schwartzbaum J, Wiklund F, Sjöström S, Liu Y, Tsavachidis S, Ahlbom A, Auvinen A, Collatz-Laier H, Feychting M, Johansen C, Kiuru A, Lönn S, Schoemaker MJ, Swerdlow AJ, Henriksson R, et al. A comprehensive study of the association between the EGFR and ERBB2 genes and glioma risk. Acta Oncologica. 2010; 49(6):767775.

31. Perry C, Agarwal D, Abdel-Fatah TM, Lourdusamy A, Grundy R, Auer DT, Walker D, Lakhani R, Scott IS, Chan $\mathrm{S}$, Ball $\mathrm{G}$ and Madhusudan S. Dissecting DNA repair in adult high grade gliomas for patient stratification in the post-genomic era. Oncotarget. 2014; 5(14):5764-5781.

32. Felsberg J, Thon N, Eigenbrod S, Hentschel B, Sabel MC, Westphal M, Schackert G, Kreth FW, Pietsch T, Loffler M, Weller M, Reifenberger G, Tonn JC and German Glioma N. Promoter methylation and expression of MGMT and the DNA mismatch repair genes MLH1, MSH2, MSH6 and PMS2 in paired primary and recurrent glioblastomas. International journal of cancer Journal international du cancer. 2011; 129(3):659-670.

33. Walter AW, Ennis S, Best H, Vaughn CP, Swensen JJ, Openshaw A and Gripp KW. Constitutional mismatch repair deficiency presenting in childhood as three simultaneous malignancies. Pediatric blood \& cancer. 2013; 60(11):E135-136.

34. Hoyer J, Ekici Arif B, Endele S, Popp B, Zweier C, Wiesener A, Wohlleber E, Dufke A, Rossier E, Petsch C, Zweier M, Göhring I, Zink Alexander M, Rappold G, Schröck E, Wieczorek D, et al. Haploinsufficiency of ARID1B, a Member of the SWI/SNF-A ChromatinRemodeling Complex, Is a Frequent Cause of Intellectual Disability. Am J Hum Genet. 2012; 90(3):565-572.

35. Santen GWE, Aten E, Sun Y, Almomani R, Gilissen C, Nielsen M, Kant SG, Snoeck IN, Peeters EAJ, HilhorstHofstee Y, Wessels MW, Hollander NSd, Ruivenkamp CAL, Ommen G-JBv, Breuning MH, Dunnen JTd, et al. Mutations in SWI/SNF chromatin remodeling complex gene ARID1B cause Coffin-Siris syndrome. Nature Genetics. 2012; 44(4):379-380.

36. Price MA, Colvin Wanshura LE, Yang J, Carlson J, Xiang B, Li G, Ferrone S, Dudek AZ, Turley EA and McCarthy JB. CSPG4, a potential therapeutic target, facilitates malignant progression of melanoma. Pigment Cell \& Melanoma Research. 2011; 24(6):1148-1157.

37. Svendsen A, Verhoeff JJC, Immervoll H, Brøgger JC, Kmiecik J, Poli A, Netland IA, Prestegarden L, Planagumà J, Torsvik A, Kjersem AB, Sakariassen PØ, Heggdal JI, Van Furth WR, Bjerkvig R, Lund-Johansen M, et al. Expression of the progenitor marker NG2/CSPG4 predicts poor survival and resistance to ionising radiation in glioblastoma. Acta Neuropathol. 2011; 122(4):495-510.

38. Kagan HM and Trackman PC. Properties and Function of Lysyl Oxidase. Am J Respir Cell Mol Biol. 1991; 5(3):206210.

39. Peinado H, del Carmen Iglesias-de la Cruz M, Olmeda D, 
Csiszar K, Fong KSK, Vega S, Nieto MA, Cano A and Portillo F. A molecular role for lysyl oxidase-like 2 enzyme in Snail regulation and tumor progression. EMBO J. 2005; 24(19):3446-3458.

40. Sadeque A, Serao NV, Southey BR, Delfino KR and Rodriguez-Zas SL. Identification and characterization of alternative exon usage linked glioblastoma multiforme survival. BMC Med Genomics. 2012; 5:59.

41. Rainer J, Lelong J, Bindreither D, Mantinger C, Ploner C, Geley S and Kofler R. Research resource: transcriptional response to glucocorticoids in childhood acute lymphoblastic leukemia. Molecular endocrinology. 2012; 26(1):178-193.

42. Pacholsky D, Vakeel P, Himmel M, Lowe T, Stradal T, Rottner K, Furst DO and van der Ven PF. Xin repeats define a novel actin-binding motif. J Cell Sci. 2004; 117(Pt 22):5257-5268.

43. Keller A, Harz C, Matzas M, Meder B, Katus HA, Ludwig $\mathrm{N}$, Fischer U and Meese E. Identification of novel SNPs in glioblastoma using targeted resequencing. PLoS One. 2011; 6(6):e18158. 